\title{
Childhood anxiety disorders prevalence in Saudi Arabia
}

\author{
Sulhi A. Alfakeh, MD, Abdulelah A. Gadah, MD, Khaled A. Alharbi, MD, Fadi M. Jan, MD, Mutasem S. Hejazi, MD, \\ Omar K. Addas, MD, Mohammed K. Alamoudi, MD, Abmed I. Al Taif, MD.
}

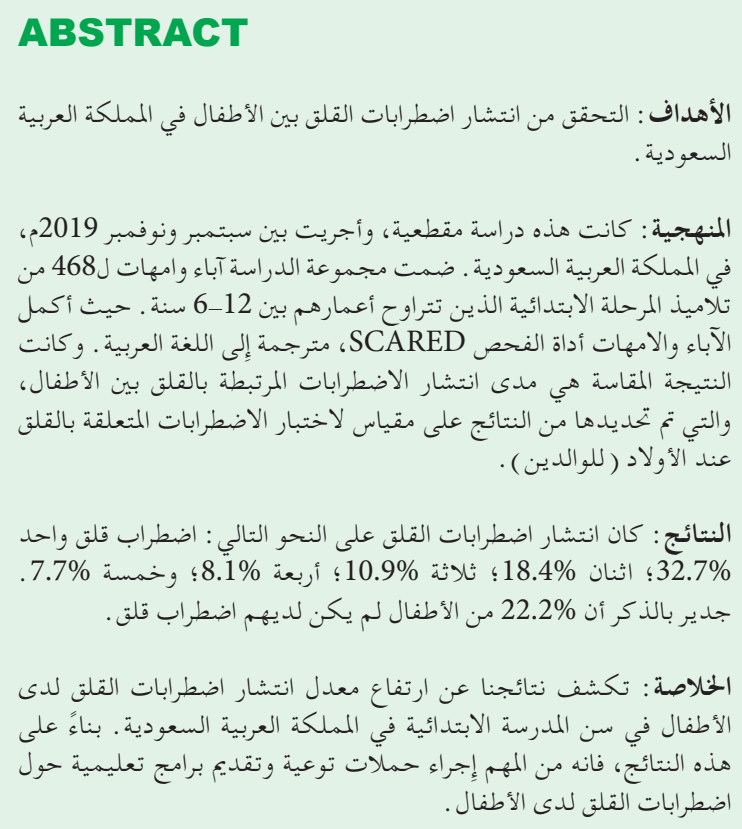

Objectives: To investigate the prevalence of childhood anxiety disorders in Saudi Arabia.

Methods: We conducted a cross-sectional study, between September and November 2019, in Saudi Arabia. The study group included the parents of 468 primary school children, aged 6-12 years. Parents completed the Screen for Child Anxiety Related Disorders (SCARED) screening instrument, translated to Arabic. The measured outcome was the prevalence of childhood anxiety disorders, determined from the scores on the SCARED instrument.

Results: Childhood anxiety disorders prevalence were as follows: $32.7 \%$ had one anxiety, $18.4 \%$ had 2 , $10.9 \%$ had $3,8.1 \%$ had 4 , and $7.7 \%$ had 5 . Of note, $22.2 \%$ of children did not have an anxiety disorder.

Conclusion: Our results reveal a high prevalence of childhood anxiety disorders among primary school age children in Saudi Arabia. Based on these findings, conducting awareness campaigns and providing educational programs on childhood anxiety disorders might be important to improve the health outcomes of children.

Keywords: anxiety, child, Saudi Arabia, prevalence

Saudi Med J 2021; Vol. 42 (1): 91-94

doi: 10.15537/smj.2021.1.25624

From the Department of Medicine, Faculty of Medicine, King Abdulaziz University, Jeddah, Kingdom of Saudi Arabia.

Received 14th August 2020. Accepted 9th December 2020.

Address correspondence and reprint request to: Dr. Sulhi A. Alfakeh, Child and Adolescent Psychiatrist Assistant Professor, Department of Medicine, Faculty of Medicine, King Abdulaziz University, Jeddah, Kingdom of Saudi Arabia. E-mail: salfakeh@kau.edu.sa ORCID ID: https://orcid.org/0000-0003-1371-876X

T he majority of anxiety disorders appear during childhood, and the median age of onset being 11 years. ${ }^{1,2}$ Prevalence of childhood anxiety disorder for children younger than 18 years of age ranges between $5.7 \%$ and $12.8 \%$ with the prevalence increasing to $32 \%$ among adolescents and adults within the community. ${ }^{1-3}$ Anxiety disorders are more frequent among females than males, with this between-gender difference ranging between 2:1 and 3:1 in adolescence. ${ }^{4} \mathrm{~A}$ recent study in Saudi Arabia reported that 34\% of Saudis and 2 in 5 Saudi youth, age 15 to 24 years, are diagnosed with a mental health condition over their lifetime, with separation anxiety being the most prevalent anxiety diagnosis, with an overall estimated prevalence of $16 \%{ }^{5,6}$ Of note is the high rate of comorbidity between anxiety disorders and other mental disorders, with major depressive disorder (MDD) being the most common of these comorbidity. ${ }^{3}$ Among most adults who have an anxiety-related disorder and depression, symptoms were first manifested during childhood or adolescence; the anxiety disorders were the most prevalent presenting 
diagnosis. ${ }^{7}$ From a public health perspective, when begun in adolescence, anxiety disorders are associated with significant morbidity and mortality, as well as increasing the risk for suicide attempts. ${ }^{8}$

Anxiety disorders are grouped under complex genetic diseases, characterized by a complex pathogenetic interaction between multiple genetic variants and environmental factors. Despite the progress in understanding anxiety disorders and the existence of evidence-based interventions for anxiety, it remains common that children and youth with anxiety disorders are not diagnosed or not adequately treated. ${ }^{9}$ Therefore, this study aims to estimate the childhood anxiety disorder prevalence in the Kingdom of Saudi Arabia in 2019.

Methods. We conducted this cross-sectional study between September and November 2019, in the Kingdom of Saudi Arabia. The study group comprised the parents of 468 primary school children 6 to 12 years of age. Parents completed the Screen for Child Anxiety Related Disorders (SCARED) screening instrument, translated to Arabic and validated. ${ }^{10,11}$ The presence and type of anxiety disorder was identified from the parentreported SCARED score.

Inclusion criteria were all children between the age of 6 to 12 who attend the primary school. The investigation was confirmed with the principles described in the Declaration of Helsinki of 1964. An approval consent was collected from parents enrolled in the study. Professor Boris Birmaher, the developer for the SCARED screening scale for childhood anxiety disorders, provided permission that we use the scale.

The Institutional Review Board (IRB) at King Abdulaziz University approved this study (reference No 695-19).

The SCARED screening instrument was distributed electronically to parents in the study participants. The Arabic version of the SCARED was used. The SCARED includes 41 items that describe different anxiety disorders: panic disorder, social anxiety disorder, separation anxiety disorder, significant school avoidance, and generalized anxiety disorder. Parents are required to rate the extent to which the descriptive phrases

Disclosure. Authors have no conflict of interests, and the work was not supported or funded by any drug company. describe their child on a 3-point Likert scale, as follows: "not true", "somewhat true" or "very true". Data was anonymized before analysis, with confidentiality and anonymity maintained throughout the study period.

Statistical analysis. Responses for each of the 41 items were entered in a spreadsheet (MS Excel) and first evaluated using descriptive statistics: the standard deviation and the mean or number and percentage as relevant for the distribution of the data (SPSS 21; IBM Inc., Armonk, NY). The normality of the distribution was evaluated using the Shapiro-Wilk test and the internal consistency of each subscale using Cronbach's alpha. P-values $<0.05$ were considered significant. The correlation between subscale scores was evaluated using Spearman's correlation coefficients. The Likert scale was translated to a numerical score as follows: '1', rarely true; '2', somewhat true, and ' 3 ', often true. Following this, the total anxiety score could be calculated on a scale from 0 to 123 . A total score $\geq 25$ was used to identify a possible anxiety disorder. The cutoff values used to identify the presence/absence of the different types of anxiety disorders on the SCARED were as follows: panic disorder, score of 7 (items 1, 6, 9, 12, 15, $18,19,22,24,27,30,34$, and 38); generalized anxiety disorder, score of 9 (items 5, 7, 14, 21, 23, 28, 33, 35, and 37); separation anxiety, score of 5 (items 4, 8, 13, $16,20,25,29$, and 31); social anxiety disorder, score of 8 (items 3, 10, 26, 32, 39, 40, and 41); and significant school avoidance, score of 3 (items 2, 11, 17, and 36).

Results. Childhood anxiety disorder prevalence among primary-school children in our study group was $42.1 \%$. The prevalence of each childhood anxiety disorders was as follows: separation anxiety disorder, 70.7\%; significant school avoidance, $32.9 \%$; and social anxiety disorder, $28.8 \%$ (Table 1). Of note, 104 children $(22.2 \%)$ did not have an anxiety disorder. Among the children with anxiety disorders, $32.7 \%(n=153)$ had one type of anxiety disorder, $18.4 \%(\mathrm{n}=86)$ had 2 types, (Table 2). Spearman's correlation was used to evaluate the co-existence of the different types of anxiety disorder (Table 3). Separation anxiety was strongly correlated to panic disorders ( $r s=0.649$ ), with moderate correlations between panic disorder and generalized anxiety disorder $(\mathrm{rs}=0.515)$, generalized anxiety disorder and social anxiety disorder ( $\mathrm{rs}=0.532$ ), and panic disorder $(\mathrm{rs}=0.492)$. Of note, significant school avoidance was moderately correlated with all previously stated anxiety disorders. Overall, there was a positive linear correlation among the different types of anxiety disorders. 
Discussion. Our major finding was approximately half $(58 \%)$ of the parents believe their primary school child has an anxiety disorder, with the following distribution of types of anxiety disorder: generalized anxiety disorder, $86.1 \%$; panic disorder, $73.3 \%$; social anxiety disorder, $71.2 \%$; and separation anxiety disorder, $29.3 \%$. Moreover, we noted that parents were aware that their child's anxiety and of its effects. Of interest

Table 1 - Frequency count of each type of child anxiety disorders $(\mathrm{N}=468)$.

\begin{tabular}{lcc}
\hline Subscale & $\mathbf{n}$ & $(\%)$ \\
\hline Anxiety disorder & 197 & $(42.1)$ \\
$\begin{array}{l}\text { Panic disorder } \\
\text { (significant somatic symptoms) }\end{array}$ & 125 & $(26.7)$ \\
Generalized anxiety disorder & 65 & $(13.9)$ \\
Separation anxiety disorder & 331 & $(70.7)$ \\
Social anxiety disorder & 135 & $(28.8)$ \\
Significant school avoidance & 154 & $(32.9)$ \\
\hline
\end{tabular}

Table 2 - The frequency of comorbid anxiety disorders ( $N=468)$.

\begin{tabular}{lcc}
\hline Combined comorbidity & $\mathbf{n}$ & $(\%)$ \\
\hline Absence of anxiety disorders & 104 & $(22.2)$ \\
One anxiety disorder & 153 & $(32.7)$ \\
Two anxiety disorders & 86 & $(18.4)$ \\
Three anxiety disorders & 51 & $(10.9)$ \\
Four anxiety disorders & 38 & $(8.1)$ \\
Five anxiety disorders & 36 & $(7.7)$ \\
Total & 468 & $(100)$ \\
\hline \multicolumn{2}{c}{ Values are presented as numbers and percentages. Forty-five percent of } \\
\multicolumn{2}{c}{ children may have 2 or more anxiety disorders } \\
\hline
\end{tabular}

was our finding that significant school avoidance was strongly correlated to another type of anxiety disorder in $67.1 \%$ of children. In agreement with previous clinical and community-based studies, ${ }^{12-14}$ our results indicate that the SCARED screening instrument has valid psychometric properties, and is valuable to screen for childhood anxiety disorders according to the Diagnostic and Statistical Manual of Mental Disorders (DSM-5) among school-age children in Saudi Arabia. Concerning the types of childhood anxiety disorders, previous studies have described a greater prevalence of separation anxiety disorder in children than in adolescents. ${ }^{15,16}$ By comparison in our study group, the score on the separation anxiety disorder subscale was greater in early than late adolescence $(10.77 \pm 2.71)$, while scores were higher in late than early adolescence on the generalized anxiety disorder $(12.77 \pm 3.68)$ and separation anxiety $(5.18 \pm 1.57)$ subscales. Compared to one local study carried out in Riyadh, Saudi Arabia where panic disorder was equal in percentage to separation anxiety disorder. ${ }^{17}$ Our study, however, concluded that separation anxiety is the most prevalent, while panic disorder was not as common as in Riyadh.

Study limitations. Unlike previous studies, we did not evaluate between-gender differences. It has been reported that females generally have significantly higher anxiety scores than males, including total anxiety, separation anxiety, and social phobia scores. ${ }^{18-20}$ Second, this study was not able to cover the wide demographic because it was not available to a broad spectrum of participants such as illiterate people and different nationalities. Future studies should be carried out with wide variety of participants and larger sample size to cover the demographic of Saudi Arabia.

In conclusion, our results reveal a high prevalence of childhood anxiety disorders among primary school age children in Saudi Arabia. Based on these findings, conducting awareness campaigns and providing

Table 3 - Correlation between anxieties subscales using Spearman's Rho.

\begin{tabular}{|c|c|c|c|c|c|}
\hline Subscale & Panic disorder & $\begin{array}{c}\text { Generalized anxiety } \\
\text { disorder }\end{array}$ & $\begin{array}{c}\text { Separation anxiety } \\
\text { disorder }\end{array}$ & $\begin{array}{l}\text { Social anxiety } \\
\text { disorder }\end{array}$ & $\begin{array}{l}\text { Significant school } \\
\text { avoidance }\end{array}$ \\
\hline Panic anxiety disorder & 1.00 & & & & \\
\hline Generalized anxiety disorder & $0.649^{*}$ & 1.00 & & & \\
\hline Separation anxiety disorder & $0.577^{*}$ & $0.515^{*}$ & 1.00 & & \\
\hline Social anxiety disorder & $0.492^{*}$ & $0.532^{*}$ & $0.516^{*}$ & 1.00 & \\
\hline Significant school avoidance & $0.552^{*}$ & $0.561^{*}$ & $0.410^{*}$ & $0.502^{*}$ & 1.00 \\
\hline
\end{tabular}


educational programs on childhood anxiety disorders might be important to improve the health outcomes of children. Further study with a larger sample size is warranted.

Acknowledgment. We also would like to thank Professor Boris Birmaher, the developer for the SCARED screening scale for childhood anxiety disorders, for providing permission to use the scale. We would like to thank Editage (www.editage.com) for English language editing.

\section{References}

1. Hill C, Waite P, Creswell C. Anxiety disorders in children and adolescents. J Paediatr Child Health 2016; 26: 548-553.

2. Ramsawh HJ, Chavira DA, Stein MB. Burden of anxiety disorders in pediatric medical settings: prevalence, phenomenology, and a research agenda. Arch Pediat Adol Med 2010; 164: 965-972.

3. Essau CA, Lewinsohn PM, Lim JX, Moon-ho RH, Rohde P. Incidence, recurrence and comorbidity of anxiety disorders in four major developmental stages. J Affect Disord 2018; 228: 248-253.

4. Beesdo K, Knappe S, Pine DS. Anxiety and anxiety disorders in children and adolescents: developmental issues and implications for DSM-V. Psychiatr Clin North Am 2009; 32: 483-524.

5. AlTwaijri Y, Al-Subaie A, Al-Habeeb A. Saudi National Mental Health Survey Technical Report. Riyadh: King Salman Center for Disability Research. 2019.

6. Tanios CY, Abou-Saleh MT, Karam AN, Salamoun MM, Mneimneh ZN, Karam EG. The epidemiology of anxiety disorders in the Arab world: a review. J Anxiety Disord 2009; 23: 409-419.

7. Creswell C, Waite P, Cooper PJ. Assessment and management of anxiety disorders in children and adolescents. Arch Dis Child 2014; 99: 674-678.

8. Wehry AM, Beesdo-Baum K, Hennelly MM, Connolly SD, Strawn JR. Assessment and treatment of anxiety disorders in children and adolescents. Curr Psychiatry Rep 2015; 17: 591.

9. McGuinness TM, Durand SC. Update on anxiety disorders in childhood and adolescence. J Psychosoc Nurs Ment Health Serv 2016; 54: 25-28.
10. Screen for Child Anxiety Related Disorders (SCARED), CHILD Version. [Updated 2012. Accessed 2019 March]. Available from URL: https://www.midss.org/sites/default/files/ scaredchild1.pdf

11. Hariz N, Bawab S, Atwi M, Tavitian L, Zeinoun P, Khani M, et al. Reliability and validity of the Arabic Screen for Child Anxiety Related Emotional Disorders (SCARED) in a clinical sample. Psychiatry Res 2013; 209: 222-228.

12. Birmaher B, Brent DA, Chiappetta L, Bridge J, Monga S, Baugher M. Psychometric properties of the Screen for Child Anxiety Related Emotional Disorders (SCARED): a replication study. JAm Acad Child Adolesc Psychiatry 1999; 38: 1230-1236.

13. Essau CA, Muris P, Ederer EM. Reliability and validity of the Spence Children's Anxiety Scale and the Screen for Child Anxiety Related emotional disorders in German children. $J$ Behav Ther Exp Psychiatry 2002; 33: 1-8.

14. Muris P, Merckelbach H, Van Brakel A, Mayer AB. The revised version of the screen for child anxiety related emotional disorders (SCARED-R): further evidence for its reliability and validity. Anxiety Stress Coping 1999; 12: 411-425.

15. Birmaher B, Khetarpal S, Brent D, Cully M, Balach L, Kaufman J, et al. The screen for child anxiety related emotional disorders (SCARED): Scale construction and psychometric characteristics. J Am Acad Child Adolesc Psychiatry 1997; 36 : 545-553.

16. Hale III WW, Raaijmakers Q, Muris P, Meeus WI. Psychometric properties of the Screen for Child Anxiety Related Emotional Disorders (SCARED) in the general adolescent population. $J$ Am Acad Child Adolesc Psychiatry 2005; 44: 283-290.

17. Yahya M, Alkhamees HA, Zaid AZ, Albuhayri ZA, Almaghrabi AH, Faisal AA, et al. The prevalence of anxiety disorders among Primary school students in Riyadh district, Saudi Arabia. Neurology (ECronicon) 2020; 12; 2: 1-8.

18. Cohen P, Cohen J, Kasen S, Velez CN, Hartmark C, Johnson $\mathrm{J}$, et al. An epidemiological study of disorders in late childhood and adolescence-I. Age and gender specific prevalence. J Child Psychol Psychiatry 1993; 34: 851-867.

19. Compton SN, Nelson AH, March JS. Social phobia and separation anxiety symptoms in community and clinical samples of children and adolescents. J Am Acad Adolesc Psychiatry 2000; 39: 1040-1046.

20. Craske MG. Fear and anxiety in children and adolescents. Bull Menniger Clin 1997; 61: A4-A36. 